\title{
ANALYSIS OF REFRIGERATION CYCLE PERFORMANCE WITH AN EJECTOR
}

\author{
Wani J. R. ${ }^{1}$, Aklilu T. Baheta ${ }^{1, a}$, Abraham D. Woldeyohannes ${ }^{2}$, and Suhaimi Hassan ${ }^{1}$ \\ ${ }^{1}$ Department of Mechanical Engineering, Universiti Teknologi PETRONAS, 31750 Tronoh, Perak, Malaysia \\ ${ }^{2}$ Caledonian College of Engineering, PO Box 2322, CPO Seeb 111, Sultanate of Oman
}

\begin{abstract}
A conventional refrigeration cycle uses expansion device between the condenser and the evaporator which has losses during the expansion process. A refrigeration cycle with ejector is a promising modification to improve the performance of conventional refrigeration cycle. The ejector is used to recover some of the available work so that the compressor suction pressure increases. To investigate the enhancement a model with $\mathrm{R} 134 \mathrm{a}$ refrigerant was developed. To solve the set of equations and simulate the cycle performance a subroutine was written on engineering equation solver (EES) environment. At specific conditions, the refrigerant properties are obtained from EES. At the design conditions the ejector refrigeration cycle achieved 5.141 COP compared to $4.609 \mathrm{COP}$ of the conventional refrigeration cycle. This means that ejector refrigeration cycle offers better COP with $10.35 \%$ improvement compared to conventional refrigeration cycle. Parametric analysis of ejector refrigeration cycle indicated that COP was influenced significantly by evaporator and condenser temperatures, entrainment ratio and diffuser efficiency.
\end{abstract}

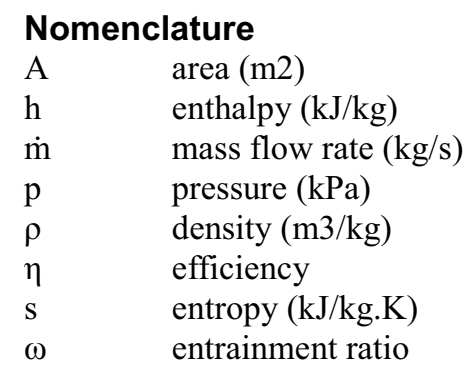

\section{Subscripts \\ d diffuser \\ $m c \quad$ mixing chamber \\ $n \quad$ nozzle \\ sn suction nozzle \\ $s \quad$ isentropic process exit \\ $1,2,3 \ldots 9$ state points}

\section{Introduction}

In a conventional vapor compression refrigeration cycle, the pressure drop from the condenser to the evaporator is done by throttling. Throttling process is always associated with loss and it is one of the thermodynamic losses. Throttling is an isenthalpic process and during this expansion process the resulted kinetic energy gain is lost by friction into the refrigerant in the form of heat. Hence, the isenthalpic expansion process forms large amount of vapor at the end of the expansion compared to isentropic expansion. Consequently, a reduction of refrigeration load in the cycle is observed. The use of two-phase ejector has become a promising cycle modification recently [1]. The potential kinetic energy is recovered by the ejector during the expansion process. The ejector also reduces the compressor work by increasing the compressor inlet pressure higher than that of the evaporator pressure which leads to a coefficient of performance (COP) improvement. There are two types of ejectors according to the position of the nozzle. These are constant pressure and constant area mixing ejectors. It was found that the performance of constant area mixing ejector is lower than the constant pressure mixing ejector [2].

There have been many attempts to study the use of ejector on performance enhancement of refrigeration cycle with different assumptions and ejector design. For instance, the COP of a refrigeration cycle with an ejector expansion device

\footnotetext{
${ }^{\mathrm{a}}$ Corresponding author: aklilu.baheta@petronas.com.my
} 
using R12 refrigerant was investigated by Kornhauser [3]. To represent the ejector process constant mixing pressure model was used and found $21 \%$ COP improvement over the conventional refrigeration cycle (CRC) under standard conditions. With R134a refrigerant, Disawas and Wongwises [4] experimentally investigated the performance of refrigeration cycle with ejector where there was no upstream expansion valve of the evaporator so that the evaporator was flooded with the refrigerant. At low heat sink temperature the test showed COP improvement over CRC. Using R134a and constant area ejector, Bilir and Ersoy [5] showed that COP increases as the difference between condenser and evaporator temperatures increases. Chen et al. [6] proposed an ejector model to predict the ejector performance at critical and sub-critical operation modes.

The performance of a refrigeration cycle also depends on the type of working fluid. As suggested by Takeuchi et al.[7], R134a gives better performance compared to R404A, R407 and R410 using ejector as an expansion device in a refrigeration cycle.

Though there have been many attempts, detailed study and analysis is still needed on ejector refrigeration cycle performance improvement compared to conventional refrigeration cycle. Thus, a refrigeration cycle with constant pressure-mixing zone ejector is analyzed and simulated using a model. Different operating conditions are considered and the cycle performance with $\mathrm{R} 134 \mathrm{a}$ refrigerant is compared to the conventional $\mathrm{R} 134 \mathrm{a}$ refrigeration cycle. In addition, parametric analysis is done to select the influential parameter/s.

\section{Ejector refrigeration cycle modeling}

Figure 1 (a) shows schematic representation of the ejector refrigeration cycle (ERC). It consists of evaporator, ejector, separator, throttling device, compressor, and condenser constituting two loops. The refrigeration loop and the power loop supply cooling effect and the driving force, respectively. First the primary (motive) fluid is accelerated in a convergent-divergent nozzle until its velocity reaches supersonic. The primary fluid entrains the secondary evaporated fluid from the evaporator, and the two fluids mix in the mixing chamber. In the diffuser, at the expense of the kinetic
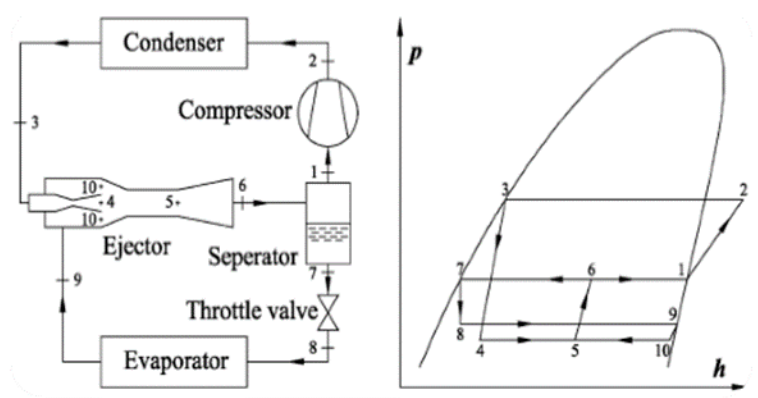

energy of the mixed fluid its pressure is increased to the separator pressure as shown in Figure 1 (b).

(a)

(b)

Figure 1. (a) Ejector refrigeration system; (b) $p$ - $h$ diagram

\section{Assumptions}

- $\quad$ pressure drop in the evaporator and condenser are assumed to be negligible,

- expansion efficiencies of the motive and suction streams are constant,

- refrigerant kinetic energies at the ejector inlet and exit are negligible, and

- shock wave loss effect is considered in the ejector diffuser efficiency.

To represent the process of the cycle, each component has been modeled using first principle.

\subsection{Nozzle Model and Analysis}

The primary nozzle exit enthalpy is determined from its isentropic relationship and given as

$$
h_{4}=h_{3}-\eta_{n}\left(h_{3}-h_{4 s}\right)
$$

Velocity of the motive fluid and cross-sectional area at the nozzle exit are given by,

$$
\begin{aligned}
& V_{4}=\sqrt{2\left(h_{3}-h_{4}\right)} \\
& A_{4}=\frac{1}{(1+\omega) \rho_{4} V_{4}}
\end{aligned}
$$

The entrainment ratio, $\omega=\dot{m}_{10} / \dot{m}_{3}$ where $\dot{m}_{10}$ and $\dot{m}_{3}$ are entrained and the primary fluid mass flow rates, respectively.

The suction chamber enthalpy at the nozzle exit is determined from its isentropic relationship and given as

$$
h_{10}=h_{9}-\eta_{s n}\left(h_{9}-h_{10 s}\right)
$$

Velocity of the secondary fluid and the cross 
sectional area at the suction nozzle exit are,

$$
\begin{aligned}
& V_{10}=\sqrt{2\left(h_{9}-h_{10}\right)} \\
& A_{10}=\frac{\omega}{(1+\omega) \rho_{10} V_{10}}
\end{aligned}
$$

For a unit total mass flow rate in the ejector diffuser, the primary and the entrained mass flow rates in terms of the entrainment ratio of the ejector are given as

$$
\dot{m}_{4}=\omega /(1+\omega) \text { and } \dot{m}_{10}=1 /\left(1+\omega^{\prime},\right.
$$

\subsection{Mixing chamber analysis}

At the ejector mixing chamber, the mixing process is done at a constant pressure. Applying the momentum and energy conservations on the mixing chamber would result relations for its exit velocity and enthalpy.

$$
\begin{gathered}
V_{5}=\sqrt{\eta_{m c}}\left(\frac{1}{(1+\omega)} V_{4}+\frac{\omega}{(1+\omega)} V_{10}\right) \\
h_{5}=\frac{1}{(1+\omega)}\left(h_{4}+\frac{V_{4}^{2}}{2}\right)+\frac{\omega}{(1+\omega)}\left(h_{10}+\frac{V_{10}^{2}}{2}\right)-\frac{V_{5}^{2}}{2}(9)
\end{gathered}
$$

\subsection{Diffuser analysis}

Similarly applying the conservation of energy and isentropic relation gives the following equations for the diffuser.

$$
\begin{gathered}
h_{6}=h_{5}+\frac{V_{5}^{2}}{2} \\
h_{6 s}=h_{5}+\eta_{d}\left(h_{6}-h_{5}\right)
\end{gathered}
$$

where $\eta_{d}$ is the diffuser efficiency and $h_{6 s}$ represents the enthalpy obtained at state 6 under isentropic process through the diffuser.

The pressure and the quality of the refrigerant at the ejector exit are determined using Eqs. (12) and (13).

$$
\begin{gathered}
p_{6}=p\left(h_{6 s}, s_{5}\right) \\
x_{6}=\frac{1}{1+\omega}
\end{gathered}
$$

\subsection{Compressor model analysis}

For a given isentropic compression process, the actual enthalpy at the exit of the compressor becomes

$$
h_{2}=h_{1}+\frac{h_{2 s}-h_{1}}{\eta_{\text {comp }}}
$$

where $\eta_{\text {comp }}$ refers to the isentropic efficiency of the compression process which is given by Eq. (15) [8].

$$
\eta_{\text {comp }}=0.874-0.0135\left(p_{2} / p_{1}\right)
$$

The rate of compressor work input is expressed by

$$
\dot{W}_{\text {comp }}=\dot{m}_{p}\left(h_{2}-h_{1}\right)
$$

The refrigeration capacity, $\dot{Q}_{\text {evap }}$ is calculated as

$$
\dot{Q}_{\text {evap }}=\dot{m}_{s}\left(h_{9}-h_{8}\right)
$$

The coefficient of performance of the ejector refrigeration cycle is defined as

$$
C O P=\dot{Q}_{\text {evap }} / \dot{W}_{\text {comp }}
$$

\subsection{Simulation input}

In order to simulate the performance of the ejector refrigeration cycle a subroutine was written in EES environment. This software has most of the refrigerant properties including R134a. Furthermore, for simulation purpose typical data given in Table 1 is used as a design conditions which was taken from [9].

Table 1. Input design conditions.

\begin{tabular}{|l|c|c|}
\hline \multicolumn{1}{|c|}{ Parameters } & $\begin{array}{r}\text { Temperature } \\
\left({ }^{\circ} \mathrm{C}\right)\end{array}$ & $\begin{array}{c}\text { Pressure } \\
(\text { bar })\end{array}$ \\
\hline Compressor exit & 80 & 7.7 \\
\hline Condenser exit & 30 & 7.7 \\
\hline Evaporator & -5 & 1.64 \\
\hline \multicolumn{1}{|c|}{ Parameters } & \multicolumn{2}{|c|}{ Specifications } \\
\hline Ejector area ratio & \multicolumn{2}{c|}{14} \\
\hline Ejector diffuser efficiency & 0.85 \\
\hline Nozzle efficiency & 0.90 \\
\hline Mixing chamber efficiency & 0.85 \\
\hline Entrainment ratio & 0.53 \\
\hline Refrigerant & \multicolumn{2}{c|}{$134 \mathrm{a}$} \\
\hline Primary mass flow rate & $0.005773 \mathrm{~kg} / \mathrm{s}$ \\
\hline Secondary mass flow rate & $0.01089 \mathrm{~kg} / \mathrm{s}$ \\
\hline
\end{tabular}

\section{Results and discussion}

Maintaining other parameters, COP of ERC was investigated for various evaporator temperatures 
ranging from $-15^{\circ} \mathrm{C}$ to $0^{\circ} \mathrm{C}$. As shown in Figure 2 COP improves as the evaporator temperature increases. This is because as the evaporator temperature increases, the pressure difference between the nozzle exit and the evaporator $\left(p_{9}-p_{4}\right)$ increases. This resulted an increases in the secondary flow rate and hence, COP and cooling capacity of the system also increased. However, the temperature of the evaporator is determined by the space to be cooled. The CRC was simulated for the same condenser and evaporator conditions. As shown in the same Figure 2, for a given evaporator temperature the COP of ERC is higher than the COP of CRC. At the design conditions the ERC achieved 5.141 COP compared to $4.609 \mathrm{COP}$ of the CRC which is $10.35 \%$ improvement compared to CRC.

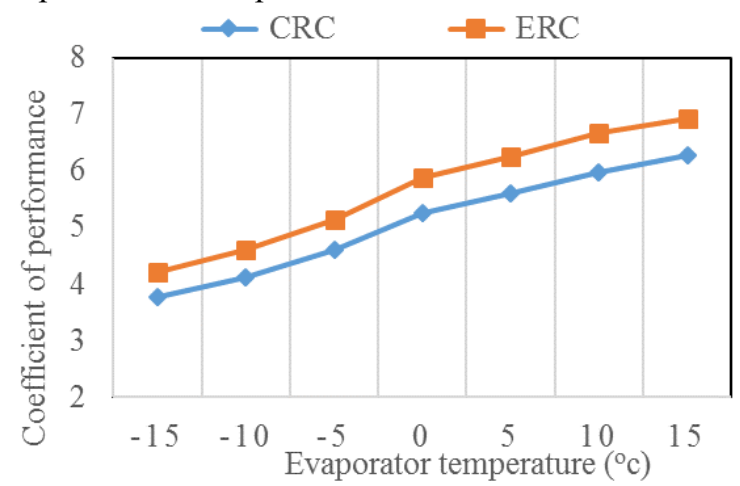

Figure 2. Variation of COP with respect to evaporator temperature

Similarly maintaining other parameters constant, the condenser exit temperature was varied from 25 to $50^{\circ} \mathrm{C}$ to study its effect on COP of the cycle. As shown in Figure 3 COP decreased with increasing condenser temperature. This is because as the condenser exit temperature increases, the enthalpy of refrigerant at the inlet to the evaporator increases. Meanwhile, the evaporator exit enthalpy remains constant and hence causing low refrigeration effect and low COP. On the other hand, to reject the heat to the surroundings the temperature of the condenser should not be below the surroundings temperature that will limit the minimum temperature. Furthermore, the COP of ERC is higher than COP of $\mathrm{CRC}$ at a given condenser exit temperature.

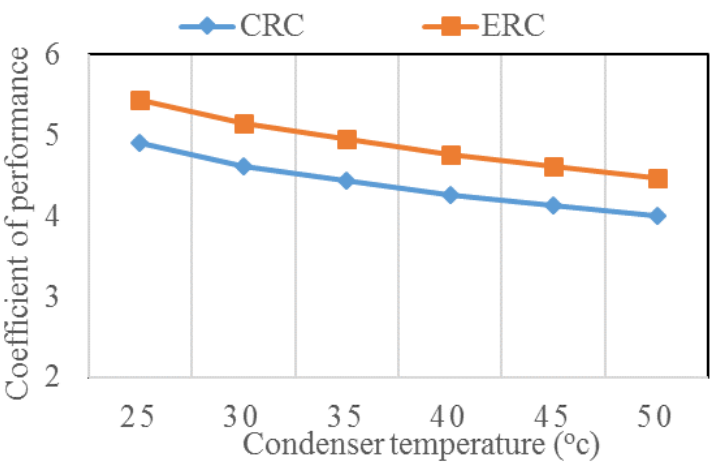

Figure 3. Variation of COP with respect to condenser temperature

Figure 4 shows COP with respect to entrainment ratio. It indicates that COP increases with increase in entrainment ratio. This is because as the entrainment ratio increases, more refrigerant is entrained by the primary fluid from the evaporator. Consequently, the mass flow rate in the evaporator increases which in turn increases the cooling capacity and the coefficient of performance.

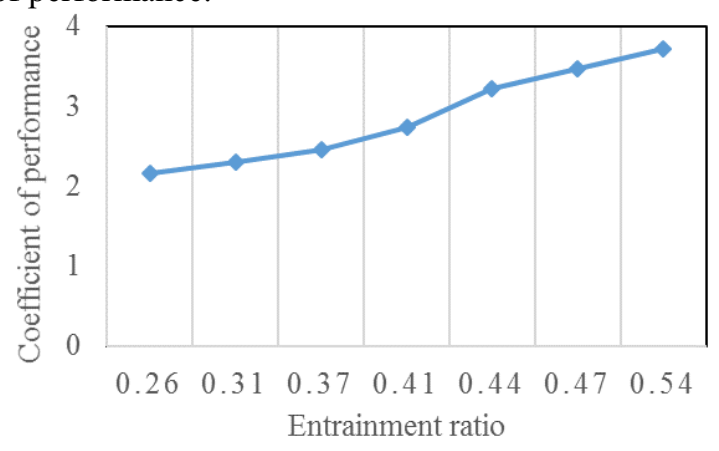

Figure 4. Variation of COP with respect to entrainment ratio

The effect of diffuser efficiency on the COP was investigated. Figure 5 indicates the higher the diffuser efficiency, the smaller the work of compression. Since better efficiency has boosted the compressor inlet pressure, less compression work is needed by the compressor for a given overall compression ratio. As a result, the COP increases as the diffuser efficiency increases as shown in Figure 5.

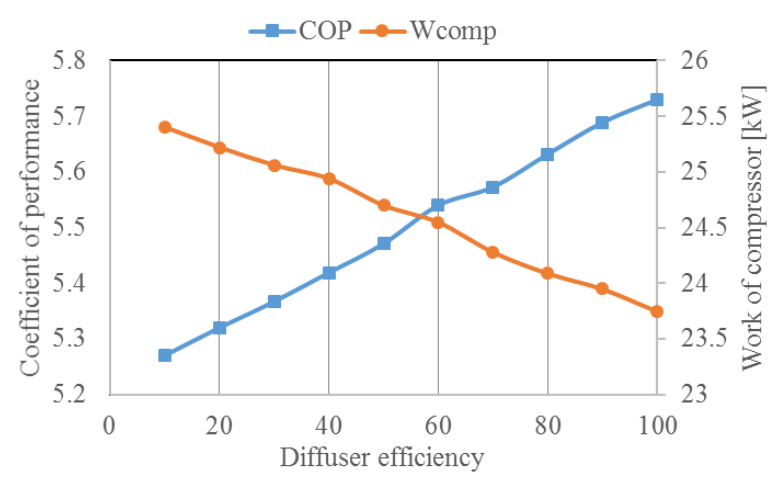


Figure 5. Variation of COP and compressor work with respect to diffuser efficiency

\section{Conclusions}

Refrigeration cycle with ejector was modeled. In order to simulate the performance of the cycle a subroutine was developed in EES environment. It was simulated for a given design conditions based on the data taken from literature. At the design conditions the ejector refrigeration cycle achieved 5.141 COP compared to 4.609 COP of the

\section{Acknowledgements}

This work was supported by Ministry of Higher Education, FRGS grant number 0153AB-I70. The authors thank Universiti Teknologi PETRONAS for providing supports to conduct the project.

\section{References}

[1] Jahar Sarkar, Ejector enhanced vapor compression refrigeration and heat pump systems: A review, Renewable and Sustainable Energy Reviews, Vol. 16, pp. 6647-6659 (2012).

[2] Riffat SB, Jiang L, Gan G., Recent development in ejector technology - a review, International Journal Ambient Energy, Vol. 26, pp 13-26 (2005).

[3] Kornhauser AA., The use of an ejector as a refrigerant expander. Proceedings of USNC/IIRPurdue refrigeration conference, USA, (1990).

[4] Disawas S, Wongwises S., Experimental investigation on the performance of the refrigeration cycle using a two-phase ejector as an expansion device, International Journal conventional refrigeration cycle. Hence, ejector refrigeration cycle offers better COP with 10.35\% improvement compared to conventional refrigeration cycle. From the parametric analysis of ERC, it was found that COP is influenced by evaporator and condenser temperatures, entrainment ratio and diffuser efficiency. Based on these outcomes, it is hoped that a better understanding of operation of ejector refrigeration cycle can be achieved. With the identification of the parameters that affect the COP significantly, future design of ejector refrigeration cycle can be improved.

Refrigeration, Vol. 27, pp. 587-94 (2004).

[5] Bilir N, Ersoy HK, Performance improvement of the vapour compression refrigeration cycle by a two-phase constant area ejector, International Journal Energy Research, Vol. 33, pp. 469-80 (2009).

[6] Chen, W., Liu, M., Chong, D., Yan, J., Little, A.B., Bartosiewicz, Y. A, 1D model to predict ejector performance at critical and sub-critical operational regimes, International Journal of Refrigeration, Vol 36 (6), pp. 1750-1761 (2013).

[7] Takeuchi H, Kume Y, Oshitani H, Ogata G. Ejector cycle system, U.S. Patent 6, 438, 993 B2 (2002).

[8] Huashan Li, Fei Cao, Xianbiao Bu, Lingbao Wang, and Xianlong Wang, Performance characteristics of R123yf and R134a ejectorexpansion refrigeration cycle, Applied energy, Vol 121, pp. 96-103 (2014).

[9] K. Ganesh Babu and K. Ravi Kumar, Usage of a two-phase ejector as expansion device to improve the performance of $\mathrm{R}-134 \mathrm{a}$ used refrigeration system (College of Eng, Chevella, Ranga Reddy-515002, Praesh, India 1977). 